\title{
Functional Morphology of Secretion by the Large Wax Glands (Sensilla Sagittiformia) Involved in Tick Defense
}

\author{
Jay A. Yoder, ${ }^{1}$ Joshua B. Benoit, ${ }^{2}$ Megan R. Bundy, ${ }^{1}$ Brian Z. Hedges, ${ }^{1}$ and Kevin M. Gribbins ${ }^{1}$ \\ ${ }^{1}$ Department of Biology, Wittenberg University, Springfield, OH 45501, USA \\ ${ }^{2}$ Department of Entomology, The Ohio State University, Columbus, OH 43210, USA \\ Correspondence should be addressed to Jay A. Yoder, jyoder@wittenberg.edu
}

Received 10 March 2009; Accepted 4 June 2009

Recommended by D. Bruce Conn

Ticks are protected against ants by release of an allomonal defense secretion from the large wax glands (or type 2 glands) that line their bodies. To explore how the large wax glands operate, before and after microscopic observations of these glands (nonsecreted versus secreted test groups), mass determinations were made for Rhipicephalus sanguineus that had been exhausted of secretion by repeated leg pinching to simulate attack by a predator. Prior to secretion, the glandular organ is fully intact histologically and matches the sensillum sagittiforme, a key taxonomic structure described in the 1940s. The large wax gland is innervated and responds to pressure stimulation as a proprioceptor that stimulates the secretory response. Histological observations after secretion has occurred show that the entire glandular contents and associated cells are jettisoned out of the gland like a syringe. The glandular cellular components are subsequently rebuilt by underlying hypodermal cells within a few days so that secretion can take place again. Presumably, the active allomonal ingredients (hydrocarbons) are released when these derived epidermal cells reach and burst onto the cuticular surface. Our conclusion is that the large wax glands are holocrine and feature intermittent regeneration.

Copyright (C) 2009 Jay A. Yoder et al. This is an open access article distributed under the Creative Commons Attribution License, which permits unrestricted use, distribution, and reproduction in any medium, provided the original work is properly cited.

\section{Introduction}

This article updates the 1949 Psyche paper of Dinnik and Zumpt's [1] that reported on the tick's secretory capacity and structure of the sensilla sagittiformia (= arrow-organs, [2], Figure 1 bottom left) that are now known as large wax glands [3] or type 2 glands [4]. These glands are dermal and present largely on dorsolateral surfaces of Metastriate ticks (include the majority of hard ticks of medical-veterinary importance except Ixodes) and they are considered key species-specific taxonomic characters $[5,6]$ for ticks in this lineage. The most notable function of the emission from these glands is its role in defense (allomone) and protection against ants $[7,8]$. The secretion has also been shown to have strong antimicrobial activity $[8,9]$. The secretion's mode of action in defense agrees with the majority of antiant allomones in insects [10]. The allomone produced by the large wax glands is rich in hydrocarbons [3] that presumably block the ant's antennal chemosensory receptors so that the tick is not recognized or neutralizes ant aggressiveness that effectively hides the ticks from the ants. This nonirritating allomone is directed specifically toward ants and no other predator $[11,12]$. One of the major components of the secretion is squalene [3] that is sequestered from the host bloodmeal (not in larvae as they have not yet fed on blood [13]). Squalene has been shown to modify tick behavior by acting as an arrestant $[14,15]$. Consistent with the arrestant function, ticks cluster around and on conspecific ticks that have secreted or aggregate on surfaces treated with the squalene secretions producing highly speciesspecific aggregations [16], thus suggesting that this secretion has a pheromonal role (synonmy of glands/pheromone associations are given in Walker et al. [4]). In Schulze's 1942 [2] initial description, he commented on the ability by these integumental organules (large wax glands) to secrete, speculating that the fluid kept the tick from drying out and was involved in chemical communication. This secretion generates no extra waterproofing to enhance water conservation by limiting cuticular permeability [17], but it is clear that this secretion from the large wax glands modifies tick behavior and has a definite semiochemical function. 
Pressure stimulation, leg pinching that simulates attack [3] or force from blood feeding $[4,18]$, prompts the large wax glands to activate and release copious amounts of secretion that appear as bursts of droplets that exude along the edges of the tick's body. The secretion evaporates as it spreads over the body, giving the tick a residual sheen. Once blown, these glands in adult ticks gradually reload (immatures have not been examined) and regain full secretory capacity after approximately 10 days [3]. Evidence of neural control of the large wax gland is apparent from the observation that a burst of secretory activity is regional and occurs onto the cuticle that is just above the leg that is being pinched $[2,3]$. Light pinching of one or several legs elicits a small pulse of secretion [7], while forceful stimulation of the entire tick (or immersion in organic solvent) causes all large wax glands to discharge their secretion simultaneously [19]. Thus, the amount of secretion corresponds with the intensity of the stimulus. Killed ticks do not secrete [3]. All Metastriate tick stages (larvae, nymphs, and adults) have large wax glands $[1,2,6]$. Furthermore, these glands secrete in all stages $[3,19]$, confirming a highly conserved, innervated glandular morphology that spans the life history of the tick as figured by Dinnik and Zumpt [1]. The morphological classification of these large wax glands has yet to be determined histologically. The goal of this study was to explore the mechanics and microscopic anatomy of how the large wax gland secretes and to account for its ability to secrete again after being depleted. We used brown dog ticks (kennel tick) R. sanguineus (Latreille) to parallel observations made by Dinnik and Zumpt [1].

\section{Materials and Methods}

2.1. Induction of Secretion from Ticks. Larvae, nymphs, and male and female adults of $R$. sanguineus were obtained from established laboratory colonies maintained at Oklahoma State University using rabbits (Oryctolagus cuniculus L.) as the host for larvae and sheep [Ovis aries (L.)] as hosts for nymphs and adults; IACUC Protocol number AG50212, Oklahoma State University, Stillwater, Okla, USA, exp. 2 May 2010. Transfer of ticks was accomplished with an aspirator. Only nonfed ticks were used in this study, and all ticks were about 2 months of age after ecdysis or hatching. In our laboratory, ticks were stored in environmental cabinets (Fisher Scientific, Philadelphia, Pa, USA) in 3000cc $(\mathrm{L} \times \mathrm{W} \times$ $\mathrm{H})$ glass desiccators at $93 \% \mathrm{RH}( \pm \mathrm{SE}<2 \% \mathrm{RH})$; saturated $\mathrm{KNO}_{3}$ at base of desiccator; [20], $25^{\circ} \mathrm{C}\left( \pm \mathrm{SE}<1.0^{\circ} \mathrm{C}\right)$ and $15 \mathrm{~h}: 9 \mathrm{~h} \mathrm{~L}: \mathrm{D}$. The $93 \% \mathrm{RH}$ is above the critical equilibrium humidity for all stages of this tick [21]. All ticks were in healthy condition and displayed regular ambulatory activity.

Ticks were induced to secrete by placing them onto the stage of a stereomicroscope (40x) and gently pinching their legs with forceps, which caused the formation of visible secretory droplets on the surface of the ticks. Larvae were treated similarly except they were anchored onto a piece of double-sided tape that was mounted on the stage of the microscope to permit observation of their secretions. When the tick's legs are pinched, typically all legs extend outward, droplets of fluid exuded out the sides of the tick's body, then the tick curls its legs under its body, and the fluid spreads over the tick's body as it evaporates. The tick remains motionless, with the legs retracted, as though playing dead, then about 30 seconds to one minute later, the tick uncurls its legs and crawls rapidly in a seemingly flight reaction $[3,7]$. To obtain ticks that did not secrete, and to act as controls, ticks were permitted to crawl onto a soft camel's hair brush, examined under the microscope while still on the brush (for absence of droplets, sheen, and behavior associated with having secreted), transferred to $1 \mathrm{cc}$ glass vials and then frozen at $-10^{\circ} \mathrm{C}$ for 3 hours and then thawed to room temperature. A closed system of HCN vapor was also used as an alternate killing method.

\subsection{Determination of Time to Replenish Secretory Reserves.} Ticks were weighed using an electrobalance $(\mathrm{SD} \pm 0.2 \mu \mathrm{g}$ precision and $\pm 6 \mu \mathrm{g}$ accuracy at $1 \mathrm{mg}$ based on five mass measurements of a $1 \mathrm{mg}$ weight at the $200 \mathrm{mg}$ range; Cahn, Ventron Co., Cerritos, Calif, USA). Ticks were weighed individually, without enclosure or anesthesia, and were transferred by lifting the tick to the weighing pan using a soft camel's hair brush. Weighing of a tick took place in less than 1 minute. In this experiment, ticks were stimulated to exhaustion (secretion was no longer produced) and then reweighed after pinching their legs again until they lost the same amount of secretion at initial stimulation [3]. Briefly, a tick was weighed, placed on the stage of a microscope, induced to secrete by pinching the legs with forceps until it could no longer secrete (typically less than 10 seconds), and then the tick was reweighed. Mass loss after stimulating the tick was primarily considered to be lost from secretions because of the short time to exhaust the ticks. The amount of mass that the tick lost was expressed as a percentage: percentage changes in mass $=100\left(w_{t}-w_{i}\right) w_{i}$, where $w_{t}$ is the mass after the tick was stimulated to exhaustion at any time $t$, and $w_{i}$ is the initial mass of the tick before its secretory reserves were exhausted. Experimental conditions were held constant at $93 \% \mathrm{RH}, 15 \mathrm{~h}: 9 \mathrm{~h} \mathrm{~L}: \mathrm{D}$, and $25^{\circ} \mathrm{C}$. Every two days after initial secretion, groups of ticks were restimulated to exhaustion and reweighed, and the time to replenish was taken as the time when the ticks emitted the same amount of material as the initial stimulation; this was conducted over a time period of 2 weeks.

The experiment was replicated three times using 10 ticks at each time point (total $N=30$ ticks at each time point) with each replicate coming from a separate rearing batch of ticks. Percentage mass change data were compared using analysis of variance (ANOVA) using an arcsin transformation for percentages [22]. Killed ticks served as controls. All killed ticks were used in freshly killed condition; that is, they had not been dead for more than 2 hours. In this experiment, nonfed adult females, nonfed adult males, nonfed nymphs, and unfed larvae were tested.

\subsection{Preparation of Tissue for Microscopic Examination.} Twenty nonfed female adult ticks were placed into two groups (ticks came from three separate rearing batches). 
Preparation of tissue was done following a technique modified from vertebrate histology [23, 24]. The nonsecreting group of ten ticks (described above) was quickly placed in cold $\left(8^{\circ} \mathrm{C}\right)$ Trump's fixative and incubated for one hour at $8^{\circ} \mathrm{C}$ (Electron Microscopy Sciences, Hatfield, Pa, USA). The other group of ten ticks was induced to secrete (described above) and then immediately placed into cold Trump's fixative and stored under refrigeration $\left(8^{\circ} \mathrm{C}\right)$. After an initial hour of fixation both groups of ticks were then cut with a razor blade midsagittally and placed back into fresh Trump's fixative and shaken with a tissue agitator at $8^{\circ} \mathrm{C}$ for 24 hours. We emphasize that the ticks that were induced to secrete were not previously killed, thus, the changes in glandular morphology are a result of secretion and not due to freezing. In fact, large wax glands from ticks that were killed by freezing (ticks were killed so as not to activate secretion by chemical treatments during tissue preparation [3, 19]) showed exact intact morphology as ticks killed with $\mathrm{HCN}$ (data not shown).

The tick midsagittal pieces were trimmed under a dissecting scope $(40 \mathrm{x})$ parasagittally until only $3 \mathrm{~mm}$ of the most lateral cuticle were present. These small sagittal sections of the body wall were dehydrated using a graded series of ethanol $(70 \%, 85 \%, 2 \times 95 \%, 2 \times 100 \%$; Sigma Chemical Co., St Louis, Mo, USA). Sections were then incubated in a $1: 2$ and $1: 1$ Spurr's plastic (Electron Microscopy Sciences, Hatfield, Pa, USA): $100 \%$ ethanol for 30 minutes each before being infiltrated in pure Spurr's plastic overnight. Next, samples were embedded and cured in fresh Spurr's plastic at $60^{\circ} \mathrm{C}$ for 48 hours in an isotemperature vacuum oven (Fisher). Using a dry glass knife and an LKB-Ultramicrotome III (LKB-Ultrotome III, LKB-Products, Produkter AB, Bromma, Sweden, Europe), serial sections $(2-3 \mu \mathrm{m})$ were cut from plastic blocks and placed on standard microscope slides. Typically 25 serial frontal sections of the body wall were made for each tick, resulting in microscopic examination of a total of approximately 250 serial sections for each group. Thus, total observations from both groups of ticks equal 500 serial sections that represent three separate rearing batches. The integumental glands were visualized within the cuticle using a basic fuchsin and toluidine blue composite stain [25].

All integumental sections were examined using an Olympus compound light microscope (Olympus America, Center Valley, Pa, USA) to ascertain the microscopic anatomy of the glands present within the lateral cuticle. Photographic images were taken at various magnifications using a SPOT digital camera (Diagnostic Systems Laboratories, Webster, Tex, USA), and plates were constructed using Adobe Photoshop CS (Adobe Systems, San Jose, Calif, USA).

\section{Results}

3.1. Anatomy of the Large Wax Gland. Considerable numbers of large wax glands are located within the most lateral integument along the entire body wall of female adults of $R$. sanguineus. Most of the distal arrow-shaped duct of the gland, along with the pore, tuft chamber, and terminal chamber lie in a frontal plane in reference to the body axis and are entirely encased within the hard chitinous portion of the integument. Figure 1 bottom right represents a schematic drawing of the entire large wax gland found in R. sanguineus. The corresponding 1942 drawing redrawn from Schulze [2] is in Figure 1 bottom left. The most conspicuous part of the gland is the distal arrow-shaped duct (Figure 1, D) that empties through a large pore (Figure 1, top, Po; Figure 2, insets) onto the surface of the cuticle. The distal duct communicates proximally through a smallcentralized opening within the floor or base (Figure 1, V) of the arrow-shaped duct (Figure 1, bottom left and right). The middle chamber of the organ called the tuft chamber is almost entirely occupied by a structure resembling a "gas-flame," "flame-cell," or a "tuft of hair" (terms used by Schulze [2]) that is known as the tuft (Figure 1, T). The base of the distal duct is heavily sclerotized and appears to act as a boundary or as valve arms that limits entry into the juxtapositioned tuft chamber (Figure 1, Tc) below. The tuft appears to be nonchitinous and transparent. The surrounding tissue just under the distal arrow-shaped duct and in close association to the middle tuft chamber and the terminal/glandular chamber appears spongy in its consistency and seems to have many elastic elements within its matrix (Figure 1, S); see Figure 2(a). This elastic material continues distally and surrounds the entire gland and makes up the boundaries/frame of the pore of the gland that opens to the body surface (Figure 1, top: B, F; Figure 2(a), insets).

The tuft in the middle chamber of the gland attaches to the robust scolopale (cuticular sheath around end of dendrite) via a filament (Figure 1, Fa) that extends into the distal portion of the terminal chamber and terminates at its meeting point with the axial fiber of sensory neurons (Figure 1, A). Where the filament of the scolopale encounters the axial fiber (Figure 1, K), a swelling occurs that is known as the knot of the scolopale [2]. The distal portion of the terminal chamber (Figure 1, Pc) lumen remains open and is occupied by the filament of the scolopale, the knot of the scolopale, the axial fiber, and the lateral projecting edges of the scolopale (Figure 1, P). The proximal lumen of the terminal chamber (Figure 1, Pc) is almost completely filled by cytoplasmic processes of the glandular cells (Figure 1, G) laterally and medially by the centralized axial fiber (Figure 1, A) that presumably extends down into the deepest recesses of the terminal chamber where it merges with sensory nerve nuclei. These neuronal cell nuclei are not visible (Figure 2(a)) in any of our sections as they are enveloped by the larger glandular cells that extend past the terminal chamber of the gland and into the actual body cavity.

3.2. Large Wax Gland before and after Secretion. Figure 2(a) shows a typical large wax gland within the integument of the ticks that were treated by freezing for three hours. The gland is completely intact and shows regular morphology as described in Figure 1. Results were similar for ticks killed with HCN. The dark-staining chitinized floor of the distal arrow-shaped duct is almost completely closed with just the tip of the tuft penetrating up into the distal duct lumen from the tuft chamber. The lips of the surface pore are constricted 


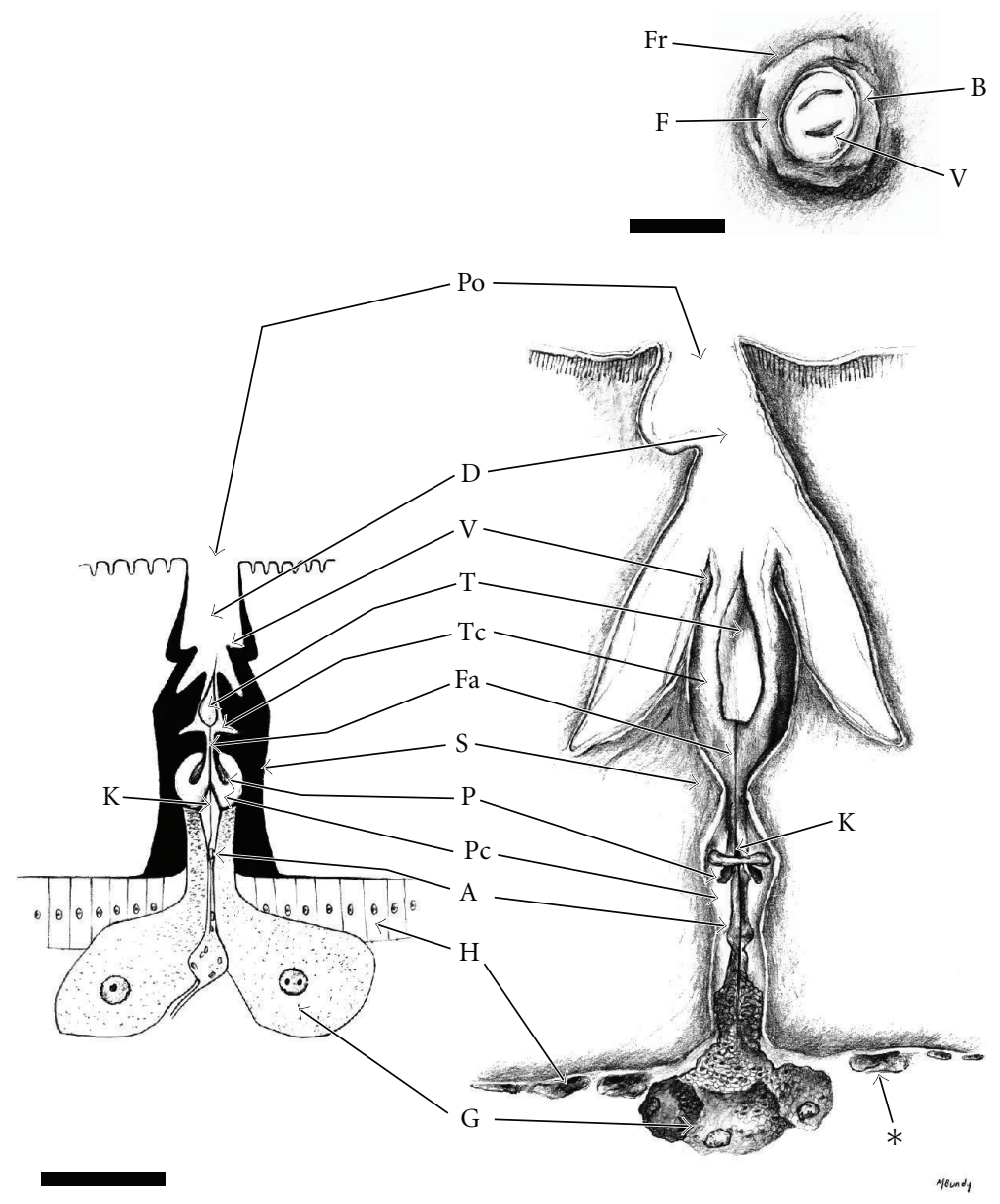

FIGURE 1: Representative drawings of the large wax glands (sensilla sagittiformia = arrow-organs) in nonfed adult females of $R$. sanguineus. Top: direct view looking down on the pore opening of the gland. Bar $=10 \mu \mathrm{m}$. This transverse view of the gland opening shows the fringe (Fr), the spongy elastic chitinous frame (F), the border of the pore opening (B), and the top of the valvular arm (V), that make up the roof of the tuft chamber. Bottom left: redrawing of the original 1942 description of the sensillum sagittiforme in sagittal view from Hyalomma marginatum Koch by Schulze [2] (also redrawn in Dinnik and Zumpt [1]). Bottom right: drawing of the large wax gland from the present study (redrawn from Figure 2(a)). Labeled structures: pore opening of gland (Po), distal arrow-shaped duct (D), valvular arm of the roof of the tuft chamber $(\mathrm{V})$, tuft $(\mathrm{T})$, tuft chamber $(\mathrm{Tc})$, anchoring filament of the tuft $(\mathrm{Fa})$, knot of the scolopale (K), spongy elastic chitin (S), projecting edges of the scolopale $(\mathrm{P})$, proximal terminal chamber $(\mathrm{Pc})$, axial sensory nerve fiber $(\mathrm{A})$, hypodermis $(\mathrm{H})$, glandular cells $(\mathrm{G})$, and enlarged juxtapositioned transdifferentiating epithelial cells $(*)$. Bar $=30 \mu \mathrm{m}$.

when looking down on the sagittal view of the gland pore opening $(10 \mu \mathrm{m})$ (Figure $2(\mathrm{a})$, inset) that is half the size of the pore opening $(22 \mu \mathrm{m})$ in the exhausted glandular organ (Figure 2(b), inset). Also, it is important to note that the right and left arms that make up both the floor of the distal duct and the roof of the tuft chamber are seen in transverse section inside of the pore opening (Figure 1: top, V; Figure 2(a), inset). The tuft, the entire scolopale, the axial fiber, and the glandular cells are all intact within the gland organ.

Ticks that were pinched on the legs with forceps causing release of secretion present a completely different morphology to their large wax glands (Figure 2(b)) than those that had not secreted. Most of the large wax gland's internal morphology has been destroyed. The lumina of the distal duct, tuft chamber, and terminal chamber appear to be greatly widened compared to the large wax glands that have not released their secretions. The tuft, some of the scolopale, the axial fiber, and the glandular cells are absent in sagittal section within exhausted large wax glands. Cytoplasmic pieces of the glandular cells are seen within the extended tuft chamber, distal duct lumen (Figure 2(b), black arrow), and on the surface of the cuticle. The chitinized arms of the floor of the arrow-shaped duct have been forced open and disappear from view within the transverse section of the pore lumen (Figure 2(b), inset). The pore lumen is also packed with broken cytoplasmic pieces of the glandular cells. The wall of the scolopale and both projecting edges are damaged but intact within the sagittal view of the exhausted organs. The spongy elastic integument surrounding the large wax gland's terminal chamber has been pushed up and thinned out in response to the widening of this proximal most chamber. The result of this relocation of the spongy elastic chitin distally has lead to an increase in this boundary material ( $25 \mu \mathrm{m}$ thick) surrounding the 


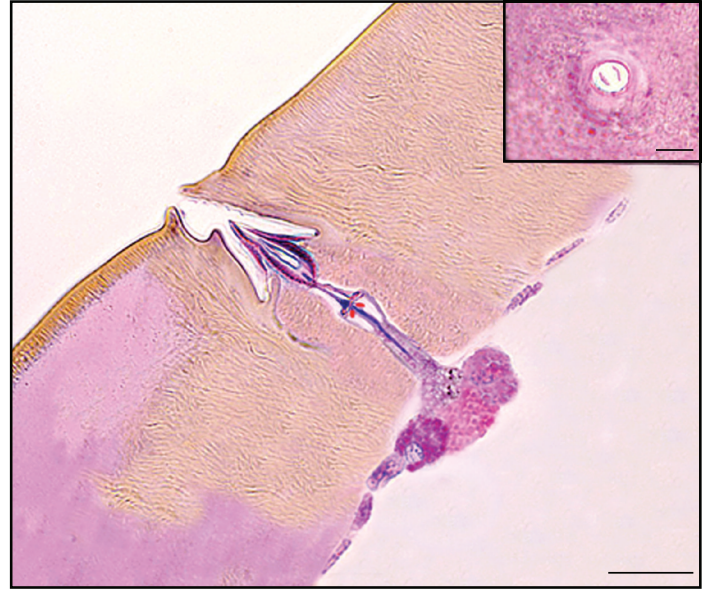

(a)

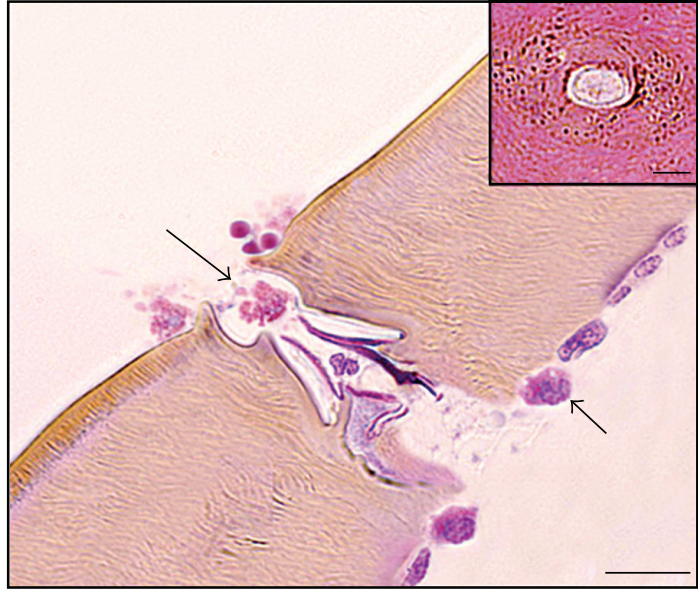

(b)

Figure 2: Micrographs of sagittal sections of large wax glands (sensilla sagittiformia = arrow-organs) in nonfed adult females of $R$. sanguineus. (a) Intact large wax gland showing regular microscopic anatomy (corresponding drawing in Figure 1 with parts labeled that match Schulze's [2] description). The gland has a restricted pore opening (inset, direct view), a thick spongy chitinous layer, and three large glandular cells occupying most of the proximal terminal chamber lumen. Bar $=30 \mu \mathrm{m}$, and Bar $=10 \mu \mathrm{m}$ (inset). (b) Evacuated large wax gland of ticks that had been stimulated to secrete. Most of the morphology of the large wax gland has been destroyed. Glandular cells have been forced up into the tuft chamber and distal duct, and as they existed under high pressure these cells have been broken into pieces (long arrow). The glandular cell pieces have forced open the pore and widened its diameter and the spongy elastic chitinous frame around the gland pore (inset). Note that juxtapositioned cells are hypertrophied and have started the differentiation process to replace glandular cells that had been ejected during release of the secretion (short arrow). Similar morphology was observed in 20 replicates, and these two micrographs are representative of those replicates. Bar $=30 \mu \mathrm{m}$, and $\mathrm{Bar}=10 \mu \mathrm{m}$ (inset).

widened pore (Figure 2(b), inset) when compared to the boundary material $(13 \mu \mathrm{m}$ thick) around the regular pore opening from an unstimulated large wax gland (Figure 2(a), inset).

Cells within the hypodermis that are in juxtaposition to these glands (Figure 2(b), white arrow) are more cuboidal in shape than the regular squamous shape of the cells that make up the majority of this epithelium. These hypodermal cells appear to have a change in cytoplasmic morphology as they mature. Most notably, these cells begin to accumulate granules within their cytoplasm as seen in Figure 2(b). These hypodermic granulated cell types, which are in close proximity to the terminal chambers, have been observed in both test groups. These morphological changes that were described for the large wax glands (Figures 1 and 2) did not occur for the numerous small glands (sensilla hastiformia = spear-organs [2]) that do not release any secretion when the tick is pressure stimulated or when the legs are pinched $[2,3]$ (data not shown). Thus, secretory release and resultant changes in gland morphology apply to the large wax glands only.

3.3. Time to Replenish Large Wax Glands. Table 1 shows initial mass of different stages and mass change data as a result of having secreted. Adult females lose $2.3 \%$ of their mass after secretory reserves have been exhausted. The amount of the secretion in males accounts for approximately the same percent difference $(2.5 \%)$ as that observed in females (ANOVA; $P>.05$ ). Nymphs lose $1.4 \%$ of their body mass after secretion and larvae lose $1.3 \%$ of their body mass
(ANOVA; $P>.05$ ) that was about one-half the amount observed in the adult stages (ANOVA; $P<.05$ ). No secretory activity was noted in freshly killed specimens at any stage (freeze/thaw or $\mathrm{HCN}$ ) and corresponds to a lack of detection of any measurable mass change after their legs are repeatedly pinched with forceps (Table 1). Upon restimulation (until the amount lost remained constant), full capacity to secrete was regained after 12 days for adult females, 10 days for adult males, 6 days for nymphs, and 8 days for larvae.

\section{Discussion}

The structure of the large wax gland in adult $R$. sanguineus shows nearly the exact microscopic anatomy as original illustrations of the sensillum sagittiforme figured by Schulze [2] and is the same in all stages of the life cycle as described by Dinnik and Zumpt [1]. This glandular organ during their discussions is labeled as a secretory gland. At no time during development are the large wax glands morphologically redundant, embryonic, or nonfunctional [1]. Indeed, all stages have large wax glands, all stages secrete from these structures when they are disturbed, and all stages are protected against predation by ants $[3,6]$ that links the morphological occurrence of these large wax glands to semiochemical functioning. The sensory function of large wax glands that Dinnik and Zumpt [1] propose is entirely correct; most likely, it is of proprioceptive nature because of the mechanical force that triggers release of secretion by these glands and the identification histologically of axial fibers of nerve cells. Thus, the sensory function of the large wax 
TABLE 1: Number of days required for the large wax glands to replenish secretion by different nonfed stages of $R$. sanguineus $\left(93 \% \mathrm{RH}, 25^{\circ} \mathrm{C}\right)$ based on restimulation (leg pinching) following initial exhaustion of secretory reserves. L, larva; N, nymph; AM, adult male; AF adult female; dead tick, killed by freezing and then thawed to room temperature (shown); $*$, results from HCN-killed were similar. Data are mean \pm SE and values followed by the same superscript letter within a column are not significantly different (ANOVA; $P<.05)$. ( $\mathrm{N}=3$ replicates of 10 ticks for each time point with each replicate coming from a separate rearing batch of ticks).

\begin{tabular}{|c|c|c|c|c|}
\hline & \multicolumn{4}{|c|}{ \% body mass lost after exhausting secretion } \\
\hline & $\mathrm{L}$ & $\mathrm{N}$ & $\mathrm{AM}$ & $\mathrm{AF}$ \\
\hline \multicolumn{5}{|l|}{ Stimulated once } \\
\hline Dead tick* & 0 & 0 & 0 & 0 \\
\hline Live tick & $1.25 \pm 0.12^{\mathrm{a}}$ & $1.39 \pm 0.24^{\mathrm{a}}$ & $2.51 \pm 0.09^{\mathrm{a}}$ & $2.33 \pm 0.17^{\mathrm{a}}$ \\
\hline \multicolumn{5}{|l|}{ Restimulation (day) } \\
\hline 0 & $0^{\mathrm{b}}$ & $0^{\mathrm{b}}$ & $0^{\mathrm{b}}$ & $0^{\mathrm{b}}$ \\
\hline 2 & $0.24 \pm 0.13^{\mathrm{c}}$ & $0.77 \pm 0.09^{c}$ & $0.39 \pm 0.11^{\mathrm{c}}$ & $0.54 \pm 0.18^{\mathrm{c}}$ \\
\hline 4 & $0.71 \pm 0.07^{\mathrm{d}}$ & $1.02 \pm 0.23^{\mathrm{d}}$ & $1.24 \pm 0.08^{\mathrm{d}}$ & $0.92 \pm 0.13^{\mathrm{d}}$ \\
\hline 6 & $0.82 \pm 0.20^{\mathrm{e}}$ & $1.41 \pm 0.14^{\mathrm{a}}$ & $1.16 \pm 0.07^{\mathrm{e}}$ & $1.73 \pm 0.16^{\mathrm{e}}$ \\
\hline 8 & $1.21 \pm 0.08^{\mathrm{a}}$ & $1.32 \pm 0.20^{\mathrm{a}}$ & $2.10 \pm 0.12^{\mathrm{f}}$ & $1.67 \pm 0.06^{\mathrm{f}}$ \\
\hline 10 & $1.30 \pm 0.09^{\mathrm{a}}$ & $1.48 \pm 0.12^{\mathrm{a}}$ & $2.44 \pm 0.07^{\mathrm{a}}$ & $2.03 \pm 0.19^{g}$ \\
\hline 12 & $1.22 \pm 0.17^{\mathrm{a}}$ & $1.41 \pm 0.15^{\mathrm{a}}$ & $2.63 \pm 0.09^{\mathrm{a}}$ & $2.29 \pm 0.24^{\mathrm{a}}$ \\
\hline 14 & $1.36 \pm 0.21^{\mathrm{a}}$ & $1.44 \pm 0.09^{\mathrm{a}}$ & $2.58 \pm 0.17^{\mathrm{a}}$ & $2.26 \pm 0.11^{\mathrm{a}}$ \\
\hline \multicolumn{5}{|l|}{ Body size } \\
\hline Initial mass (mg) & $0.0347 \pm 0.003$ & $0.147 \pm 0.009$ & $2.16 \pm 0.54$ & $3.32 \pm 0.26$ \\
\hline
\end{tabular}

gland is to perceive changes by stretching, pressure (cuticular deformation), or shifts in the chitinous exoskeleton that activates the secretory response. Schulze [2] alludes to such a mode of activation of the sensilla sagittiformia (large wax glands) as well.

From this study it is clear that the large wax gland is a holocrine pressure-secreting gland; therefore, the tick allomonal defense secretion is a holocrine secretion. Until now classification of the large wax gland based on how it operates was not known. Our criteria for assigning a holocrine function to the large wax gland include (modified from Fawcett [26]): (1) there is no conduit for the secretory material to reach the cuticular surface because the scolopale projecting edges prevent communication between the terminal chamber proximally and the distal duct chamber, thus ruling out the possibility of a secretion that is merocrine or apocrine in origin; (2) essentially the entire organ is gutted from the inside out in response to physical stimulus to the cuticle; (3) entire intact cells, or large fragments of cells, are ejected from the gland onto the cuticular surface. The long chain hydrocarbons that are the active ingredients of the allomone and function to hide the tick from ants [12] are likely liberated from the cells (so-called derived epidermal cells) when they are ejected and burst onto the cuticular surface. Release of internal contents when the cells burst probably serves an additional purpose by providing a sticky, viscous-type of consistency to the exudates, and this is also a characteristic of certain allomones that function uniquely against ants. The presumed function of such a viscous secretion is to facilitate clogging of the ant's antennal chemosensory receptors, along with blocking by the hydrocarbons, so that the tick goes undetected or is invisible to the ants chemoreception (modified from Whitman et al. [10]).

Based on morphology and collected data from this study we speculate the following mechanism for how this gland may function. In response to pressure stimulating the tick's legs, or entire body, by pinching or pressing with forceps, the physical forces produced from the forceps likely pull or stretch the exoskeleton that cause bending of the tuft within the tuft chamber. This stimulates the axial fiber of the sensory neurons that is directly linked to the tuft through the filament and knot of the scolopale. The nerve action potential produced from the bending of the tuft is sent to adjacent neurons causing the tick to respond by extending its legs out behaviorally followed by an immediate retraction of the legs under the body and remaining motionless for several minutes as though dead [3]. Conceivably, all of this muscle movement produces a burst of increased hydrostatic pressure that forces the glandular cells up into the distal terminal chamber and also causes wave-like rebound movements of the spongy elastic chitin surrounding the gland. As the cells are forced up into the terminal chamber they widen the chamber width and push the spongy compressible boundary material against adjacent cuticle that is more stable and stretch resistant. This forces the spongy elastic material to move in one direction, up toward the surface of the integument. The whole process of hydrostatic forces and the movement of the spongy boundary material facilitate the inside of the gland to widen and push the glandular cells up toward the surface. The large glandular cells' forceful ejection destroys the floor of the scolopale and tuft and forces the glandular cell debris into the lumen of the distal arrow duct and out the pore onto the surface of the cuticle. 
Microscopic analysis of the large wax gland after having secreted also provides insight into how the gland renews and has the ability to secrete again. Like the majority of defense secretions it is delivered frugally $[7,10]$, but necessitates the replenishment of the proximally located glandular cells and associated structures because the secretion is holocrine based on the present data. All glandular cells are typically epithelial in origin that includes the hypodermal cell layer under the cuticle $[26,27]$. Microscopic examination reveals that the glandular cells transdifferentiate from the squamous epithelial cells that make up hypodermis. This transdifferentiation includes a change in shape of the cells adjacent to the gland from squamous to cuboidal and a change in cytoplasmic morphology from an ungranulated to heavily granulated cytostol. This is also suggested from the observations of Schulze [2] where these cells are called regenerative cells. The nearly complete destruction internally of the large wax gland caused by forceful secretion of the basal glandular cells indicates that the glands would be nonfunctional for a long period of time as they are rebuilt, requiring many days (this study [3]). The complete exhaustion of all large wax glands on a tick, however, is unlikely to occur in a natural setting. Delivery of the defense secretion in slight pulses [3] and aimed at the site of attack (thus, not all tick's large wax glands secrete at any one time) requires that such cellular restoration occur, only intermittently, and this is consistent with the frugal delivery that characterizes allomonal defense secretions [10] so as not to be rendered totally defenseless. Also, as evidenced in unstimulated ticks (not secreted), the cells adjacent to intact glands have already started the differentiation process; thus, if a gland is exhausted it recovers more quickly because the regeneration process has already been started or even completed before the gland secretes.

\section{References}

[1] J. Dinnik and F. Zumpt, "The integumentary sense organs of the larvae of the Rhipicephalinae (Acarina)," Psyche, vol. 56, no. 1, pp. 1-17, 1949.

[2] P. Schulze, "Über die Hautsinnesorgane der Zecken, besonders über eine bisher unbekannte Art von Arthropodensinnesorganen, die Krobylophoren," Zeitschrift für Morphologie und Ökologie der Tiere, vol. 38, no. 2, pp. 379-419, 1942.

[3] J. A. Yoder, R. J. Pollack, A. Spielman, D. E. Sonenshine, and D. E. Johnston, "Secretion of squalene by ticks," Journal of Insect Physiology, vol. 39, no. 4, pp. 291-296, 1993.

[4] A. R. Walker, C. M. Lloyd, K. McGuire, S. J. Harrison, and J. G. Hamilton, "Integumental glands of the tick Rhipicephalus appendiculatus (Acari: Ixodidae) as potential producers of semiochemicals," Journal of Medical Entomology, vol. 33, no. 5, pp. 743-759, 1996.

[5] C. M. Clifford and G. Anastos, "The use of chaetotaxy in the identification of larval ticks (Acarina: Ixodidae)," Journal of Parasitology, vol. 46, no. 5, pp. 567-578, 1960.

[6] J. S. H. Klompen, J. E. Keirans, N. A. Filippova, and J. H. Oliver, "Idiosomal lyriffisures, setae, and small glands as taxonomic characters and potential indicators of ancestral segmentation patterns in larval Ixodidae (Acari: Ixodidae)," International Journal of Acarology, vol. 22, no. 2, pp. 113-134, 1996.
[7] J. A. Yoder, R. J. Pollack, and A. Spielman, "An antdiversionary secretion of ticks: first demonstration of an acarine allomone," Journal of Insect Physiology, vol. 39, no. 5, pp. 429-435, 1993.

[8] C. Pavis, H. Mauleon, N. Barre, and M. Maibeche, "Dermal gland secretions of tropical bont tick, Amblyomma variegatum (Acarina: Ixodidae): biological activity on predators and pathogens," Journal of Chemical Ecology, vol. 20, no. 7, pp. 1494-1503, 1994.

[9] J. B. Benoit, J. A. Yoder, J. T. Ark, and E. J. Rellinger, "Growth response to squalene, a tick allomonal component, by fungi commonly associated with the American dog tick, Dermacentor variabilis (Say)," International Journal of Acarology, vol. 31, no. 3, pp. 269-275, 2005.

[10] D. W. Whitman, M. S. Blum, and D. Alsop, "Allomones: chemicals for defense," in Insect Defenses: Adaptive Mechanisms and Strategies of Prey and Predators, D. L. Evans and J. O. Schmidt, Eds., pp. 289-351, State University of New York Press, Albany, NY, USA, 1990.

[11] J. A. Yoder and M. E. Brunet, "Evaluation of squalene as a potential fire ant repellent," Proceedings of the Louisiana Academy of Sciences, vol. 57, pp. 1-5, 1995.

[12] J. A. Yoder and J. L. Domingus, "Identification of hydrocarbons that protect ticks (Acari: Ixodidae) against fire ants (Hymenoptera: Formicidae), but not lizards (Squamata: Polychrotidae), in an allomonal defense secretion," International Journal of Acarology, vol. 29, no. 1, pp. 87-91, 2003.

[13] J. A. Yoder, T. L. Wittenberg, and G. J. Blomquist, "Dietarycontribution to the defense secretion of Ixodid ticks," in Acarology IX: Proceedings, R. Mitchell, D. J. Horn, G. R. Needham, and W. C. Welbourn, Eds., pp. 713-714, Ohio Biological Survey, Columbus, Ohio, USA, 1997.

[14] J. A. Yoder, J. T. Ark, and D. R. Marous, "Use of squalene and phenolic pheromone derivatives on nonfed stages of the brown dog tick, Rhipicephalus sanguineus (Latreille) (Acari: Ixodidae), with observations for attraction potential," International Journal of Acarology, vol. 34, no. 2, pp. 191-195, 2008.

[15] T. C. Cameron and A. S. Bowman, "Squalene is an arrestant for the sheep tick Ixodes ricinus," Medical and Veterinary Entomology. In press.

[16] J. A. Yoder, "Allomonal defence secretions of the American dog tick Dermacentor variabilis (Acari: Ixodidae) promote clustering," Experimental and Applied Acarology, vol. 19, no. 12, pp. 695-705, 1995.

[17] J. A. Yoder and J. A. Peterson, "Large dermal gland secretions in ticks (Acari: Ixodidae) provide no water-proofing to the integument," International Journal of Acarology, vol. 24, no. 4, pp. 341-344, 1998.

[18] Y. Rechav, C. Drey, L. J. Fielden, and M. Goldberg, "Production of pheromones by artificially fed males of the tick Amblyomma maculatum (Acari: Ixodidae)," Journal of Medical Entomology, vol. 37, no. 5, pp. 761-765, 2000.

[19] P. R. Wilkinson, "Permeability of the sagittiform sensilla in ixodid ticks, and their possible relation to hygroreception," The Canadian Entomologist, vol. 97, no. 10, pp. 1116-1118, 1965.

[20] P. W. Winston and D. S. Bates, "Saturated solutions for the control of humidity in biological research," Ecology, vol. 41, no. 1, pp. 232-237, 1960.

[21] J. A. Yoder, J. B. Benoit, E. J. Rellinger, and J. L. Tank, "Developmental profiles in tick water balance with a focus on the new Rocky Mountain spotted fever vector, Rhipicephalus 
sanguineus," Medical and Veterinary Entomology, vol. 20, no. 4, pp. 365-372, 2006.

[22] R. R. Sokal and F. J. Rohlf, Biometry: The Principles and Practice of Statistics in Biological Research, W. H. Freeman, San Francisco, Calif, USA, 1995.

[23] K. M. Gribbins, R. M. Elsey, and D. H. Gist, "Cytological evaluation of the germ cell development strategy within the testis of the American alligator, Alligator mississippiensis," Acta Zoologica, vol. 87, no. 1, pp. 59-69, 2006.

[24] K. M. Gribbins, J. L. Rheubert, M. H. Collier, D.S. Siegel, and D. M. Sever, "Histological analysis of spermatogenesis and the germ cell development strategy within the testis of the male Western Cottonmouth Snake, Agkistrodon piscivorus leucostoma," Annals of Anatomy, vol. 190, no. 5, pp. 461-476, 2008.

[25] M. A. Hayat, Stains and Cytochemical Methods, Plenum Press, New York, NY, USA, 1993.

[26] D. W. Fawcett, Bloom and Fawcett, A Textbook of Histology, Chapman and Hall, New York, NY, USA, 12th edition, 1994.

[27] J. L. Nation, Insect Physiology and Biochemistry, CRC Press, Boca Raton, Fla, USA, 2001. 

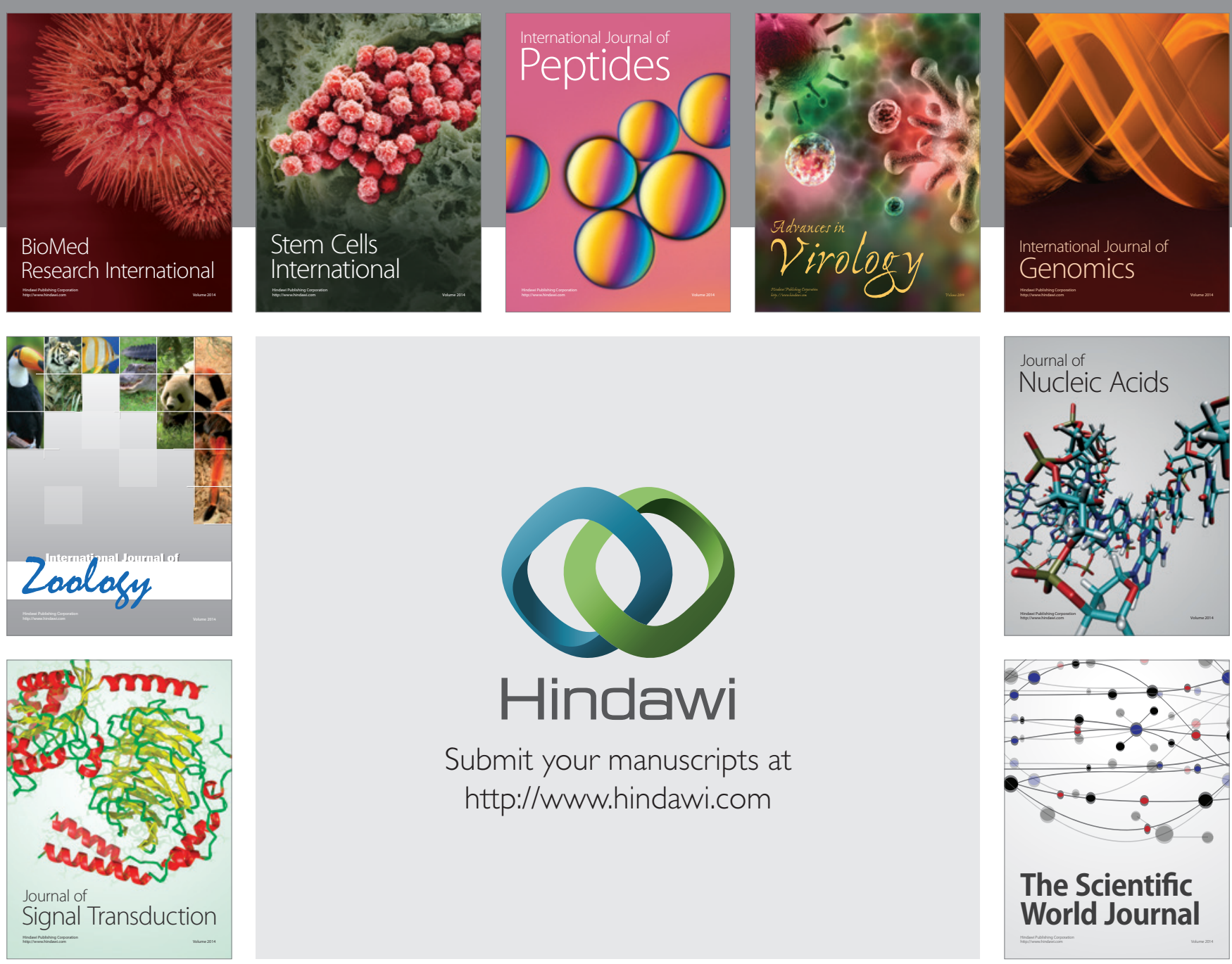

Submit your manuscripts at

http://www.hindawi.com
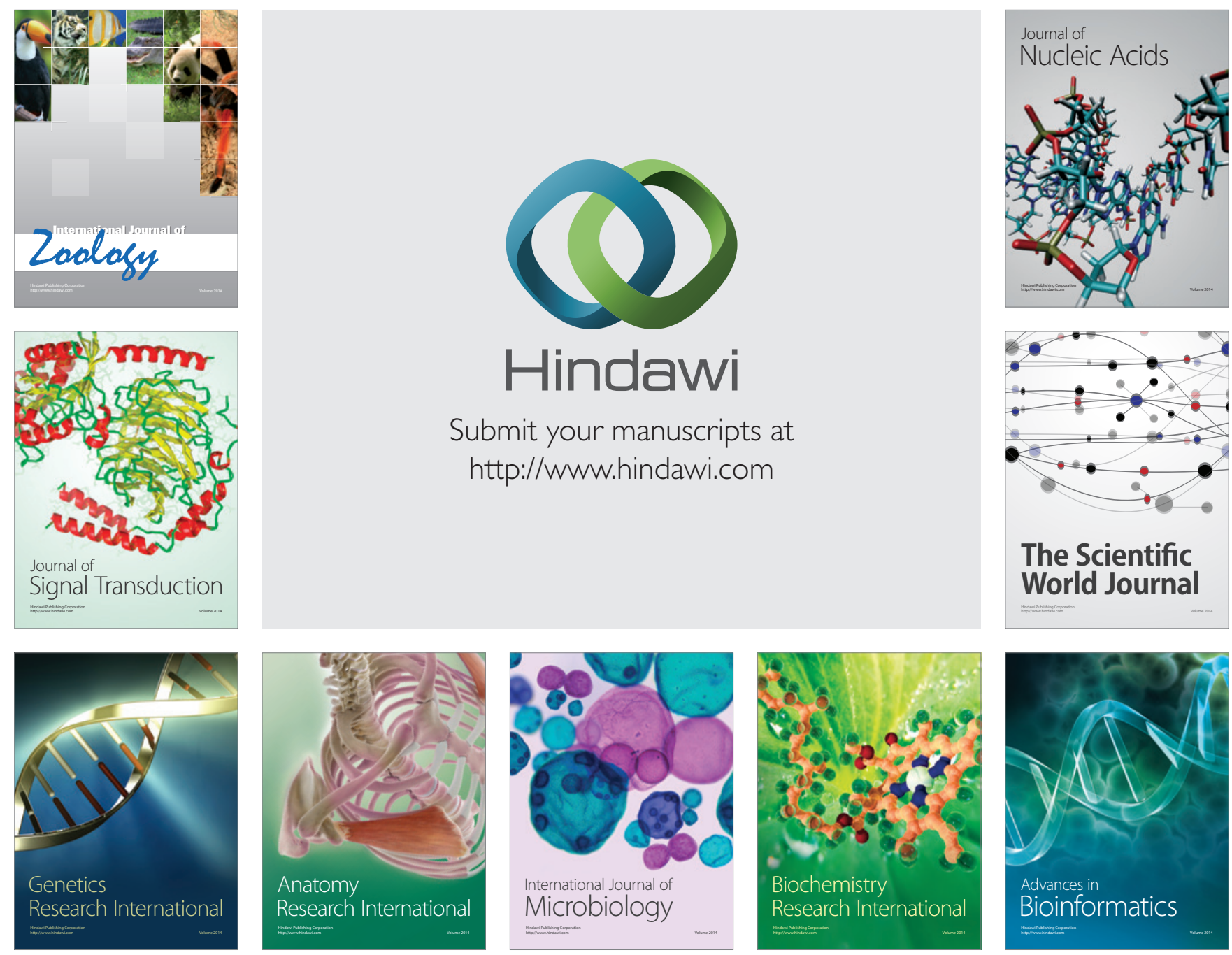

The Scientific World Journal
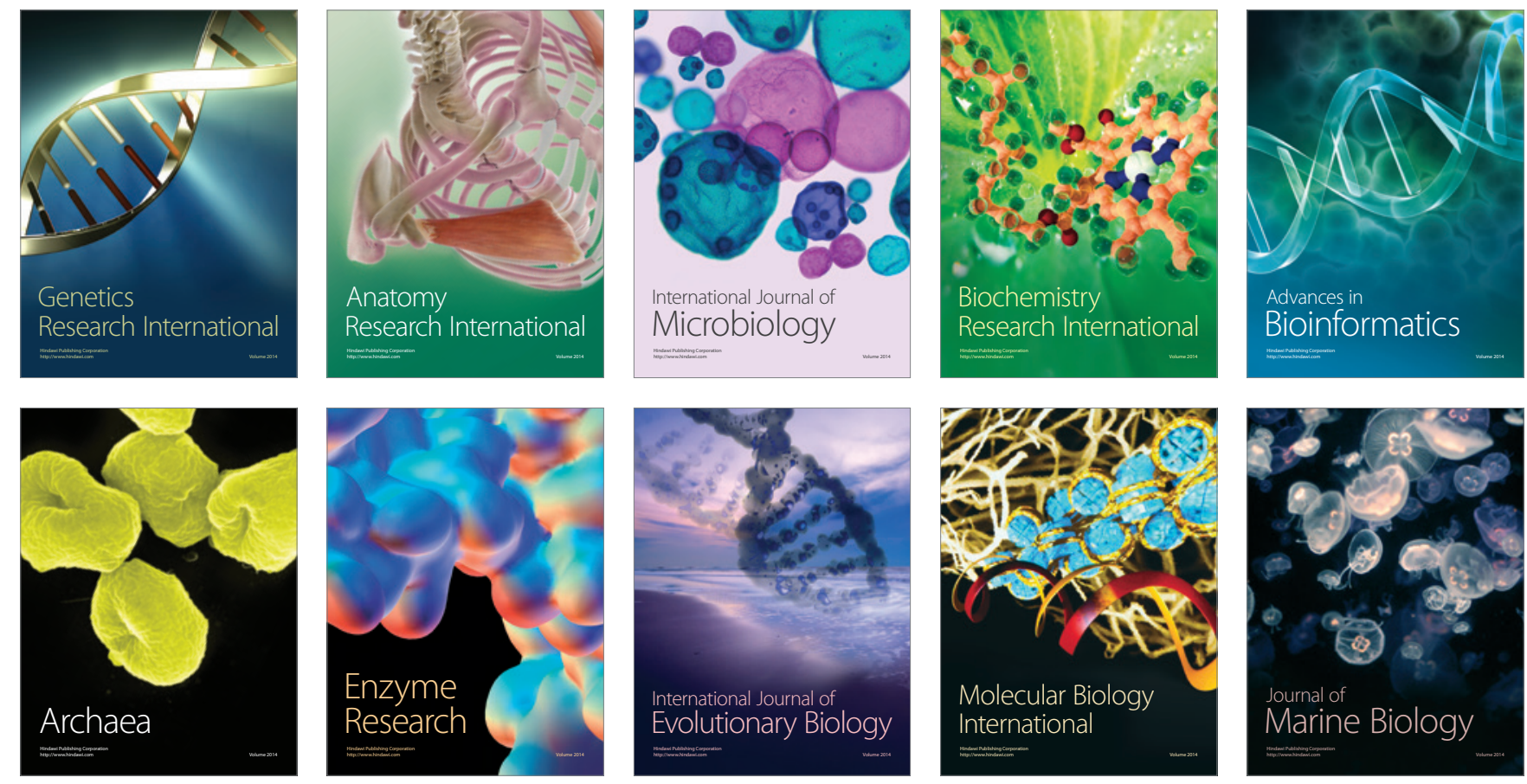